\title{
ASSOCIATION OF HUMAN CHORIONIC GONADOTROPHIN WITH PREGNANCY INDUCED HYPERTENSION
}

\author{
Nayab Afzal Chatha, Humaira Osman Jaffery, Saima Qamar, Nilofar Mustafa, Rizwana Kamran, Viqar Ashraf \\ Combined Military Hospital (CMH) Lahore Medical College, Lahore/National University of Medical Sciences (NUMS) Pakistan
}

\begin{abstract}
Objective: To determine the positive predictive value of beta Human Chorionic Gonadotrophin in early second trimester for predicting pregnancy induced hypertension.

Study Design: Cross-sectional study.

Place and Duration of Study: Department of Obstetrics and Gynaecology Combined Military Hospital, Lahore, from Jun 2017 to Nov 2017.

Methodology: A total of 214 female pregnant patients met the criteria for inclusion in this study. Patients with beta human chorionic gonadotrophin ( $\beta \mathrm{Hcg}$ ) levels $\geq 2 \mathrm{MoM}$ were followed at 22, 26, 30 and 34 weeks of gestation. Blood pressure was monitored. Pregnancy induced hypertension (PIH) was labelled after 20 weeks (as per dating scan) of gestation in patients who did not have proteinuria ( $\geq 300 \mathrm{mg} 24$ hour urine sample) and had a systolic blood pressure $\geq 140 \mathrm{mmHg}$ and/or a diastolic blood pressure $\geq 90 \mathrm{mmHg}$ (blood pressure readings taken at two separate points in time four hours apart).

Results: Patients ranged between 18-35 years of age, with the mean age being $27.3 \pm 4.3$ years. Mean gestational age was observed to be $15.6 \pm 1.8$ weeks. Mean BMI was $23.8 \pm 3.2 \mathrm{~kg} / \mathrm{m}^{2}$. Out of 214 patients, 30 patients $(14 \%)$ had beta human chorionic gonadotrophin level $>2$ MoM. Out of these 30 patients, 25 patients $(83.3 \%)$ developed $\mathrm{PIH}$. There were 100 primigravida (46.7\%) and 114 multigravidas (53.3\%). Beta human chorionic gonadotrophin in predicting pregnancy induced hypertension showed sensi-tivity of $96.1 \%$, a specificity of $97.3 \%$, with a PPV $83.3 \%$, a NPV $99.4 \%$ and diagnostic accuracy of $97.2 \%$.

Conclusion: Pregnant women with beta human chorionic gonadotrophin levels >2 MoM at 13-18 weeks gestation were at an increased risk of developing pregnancy induced hypertension.
\end{abstract}

Keywords: Beta human chorionic gonadotropin ( $\beta-\mathrm{HCG}$ ), Positive predictive value, pregnancy induced hypertension.

This is an Open Access article distributed under the terms of the Creative Commons Attribution License (http://creativecommons.org/licenses/by/4.0), which permits unrestricted use, distribution, and reproduction in any medium, provided the original work is properly cited.

\section{INTRODUCTION}

Pregnancy induced hypertension $(\mathrm{PIH})$ is a major global medical condition affecting both the pregnant women and the fetus 1,2 . The incidence of this disorder varies geographically from $6-8 \%$ to as high as $12-15 \%$ of all pregnant women especially in developing countries ${ }^{3}$. As the name implies, pregnancy induced hypertension is exclusively encountered in pregnancy, and is a major contributor to maternal and perinatal morbidity 4 . Although adequate prenatal care combined with diligent surveillance for signs of pre-eclampsia and prompt intervention has reduced the number of poor outcomes, maternal and fetal morbidity

Correspondence: Dr Saima Qamar, Department of Gynaecology, CMH Lahore Medical College, Lahore Pakistan

Received: 31 Oct 2019; revised received: 08 Dec 2019; accepted: 10 Dec 2019 still occurs ${ }^{5}$. The National High Blood Pressure Education Program Working group in pregnancy categorizes hypertension in pregnancy into four categories, chronic hypertension, gestational hypertension, pre-eclampsia, and pre-eclampsia super imposed on chronic hypertension ${ }^{6}$.

Maternal age, familial aggregation, race, smoking, history of hypertension in parents, family history of diabetes, socioeconomic level, diet, BMI and climate are identified risk factors of $\mathrm{PIH}, 8,9$.

The pathogenesis of the disease remains poorly understood. Abnormal placentation in the second trimester has been suggested as the initial culprit $^{10}$. Hypothetically it is proposed that immunological changes in the trophoblast causes a secretory response with elevation of beta Human 
Chorionic Gonadotrophin levels. Furthermore it is suggested that blood vessel damage in the placenta in pre-eclamptic patients leads to decreased oxygen perfusion, which ultimately causes an increase in $\beta$-HCG production by syncytiotrophoblasts. Levels of serum $\beta$-HCG can act as a predictor for $\mathrm{PIH}$, and can aid in stratifying patients that are destined to encounter $\mathrm{PIH}$ in the very same pregnancy ${ }^{1}$.

We conducted our study to determine the positive predictive value of beta HCG in early prediction of high risk patients for $\mathrm{PIH}$, to use this for vigilant monitoring and timely management of the disease, as well as curtailing the maternal mortality and morbidity and fetal complications associated with PIH.

\section{METHODOLOGY}

Our cross-sectional study was conducted atthe Department of Obstetrics and Gynaecology, Combined Military Hospital, Lahore and ran for a duration of six months in total (June 2017 to November 2017).

A sample size of 214 was calculated with $95 \%$ confidence level and 5\% margin of error while taking expected positive predictive value of beta HCG in predicting PIH to be $83.33 \% 11$. The technique used for sampling was non-probability consecutive sampling. Patients included in the study were gravid females (13-18 weeks of gestation as per dating scan) having $\geq 2$ MoM (multiple of median for gestational age) beta HCG levels were suspected to have $\mathrm{PIH}$ as they were having significantly raised levels of beta HCG.

Patients with twin pregnancy or fetal anomaly on ultrasound were excluded from the study. Patient with diabetes women already on antihypertensive medication, patients with liver disorder (bilirubin $>1.2 \mathrm{mg} / \mathrm{dl}$ ) or renal disorder (serum creatinine $>1.2 \mathrm{mg} / \mathrm{dl}$ ) were also excluded.

After having been approved by the ethical review committee (435/ERC/CMHLMC) of the hospital, data was collected for 214 gravid females who presented in the outpatient department of Combined Military Hospital, Lahore and ful- filled the outlined criteria above were counselled and explained the details of the study. Written informed consent and detailed history was taken from each patient.

Gravid females after 20 weeks of gestation (as per dating scan) having a systolic blood pressure (SBP) equal to or more than $140 \mathrm{mmHg}$, and/or those with a diastolic blood pressure $(\mathrm{DBP}) \geq 90 \mathrm{mmHg}$ (at two separate points in time four hours apart) without proteinurea ( $\geq 300 \mathrm{mg}$ 24 hours urine sample) were followed up on $22,26,30$ and 36 weeks. Blood pressure was taken using mercury sphyg-momanometer. All the data were noted and recorded on a proforma along with demographic details of the patient. All the lab tests were carried out in the same lab $(\mathrm{CMH}$ $\mathrm{Lab}$ ) and all the blood pressure recordings were done on the same blood pressure apparatus to eliminate bias, confounding variables were controlled by exclusion. All of the aforementioned data was compiled and analysed in SPSS version 20.0. Numerical variables i.e. age and gestational age at the time of presentation were presented by mean $\pm S D$.

Categorical variables i.e Parity and positive predictive value (PPV) $\mathrm{n}$ of beta HCG were presented as frequency and percentage. Post stratification chi-square test was applied taking value of $\leq 0.05$ as statistically significant.

\section{RESULTS}

A total of 214 patients were included in the study and demographic features are shown in table-I. Out of 214 patients 30 patients (14\%) had beta HCG level $>2 \mathrm{MoM}$. Out of these 30 patients in 25 patients $(83.3 \%)$, developed PIH.

Table-II shows sensitivity, specificity, positive predictive value and negative predictive value (NPV) of beta HCG in the prediction of gestational hypertension with a diagnostic accuracy $97.2 \%$.

Stratification for gestational age and beta HCG value in predicting pregnancy induced hypertension are shown in table-III with diagnostic accuracy of $98.6 \%, 98.1 \%$ and $95.4 \%$ in 
patients between the gestational age of 13-14 weeks, 15-16 weeks and 17-18 weeks of gestation.

Table-I: Demographic variables.

\begin{tabular}{|c|c|c|}
\hline Characteristics & Number & Percentage $(\%)$ \\
\hline \multicolumn{3}{|l|}{ Age (years) } \\
\hline $18-25$ & 82 & 38.3 \\
\hline $26-35$ & 132 & 61.7 \\
\hline Mean \pm SD & \multicolumn{2}{|c|}{$27.3 \pm 4.3$} \\
\hline \multicolumn{3}{|c|}{ Gestational Age (Week) } \\
\hline $13-14$ & 74 & 64.6 \\
\hline $15-16$ & 53 & 24.8 \\
\hline $17-18$ & 87 & 40.7 \\
\hline Mean \pm SD & \multicolumn{2}{|c|}{$15.6 \pm 1.8$} \\
\hline \multicolumn{3}{|l|}{ BMI $\left(\mathrm{kg} / \mathrm{m}^{2}\right)$} \\
\hline$\leq 25$ & 147 & 68.7 \\
\hline$\geq 25$ & 67 & 31.3 \\
\hline Mean \pm SD & \multicolumn{2}{|c|}{$23.8 \pm 3.2$} \\
\hline \multicolumn{3}{|l|}{ Parity } \\
\hline Primigravida & 100 & 46.7 \\
\hline Multigravida & 114 & 53.3 \\
\hline \multicolumn{3}{|l|}{ Beta HCG level } \\
\hline$>2 \mathrm{MOM}$ & 30 & 14 \\
\hline$<2 \mathrm{MOM}$ & 184 & 86 \\
\hline
\end{tabular}

Pregnancy induced hypertension (PIH) among cases having beta HCG $>2$ MOM level $n=30$

\begin{tabular}{l|c|c}
\hline PIH & Number & Percentage (\%) \\
\hline Yes & 25 & 83.3 \\
\hline No & 5 & 16.7 \\
\hline
\end{tabular}

\section{DISCUSSION}

Numerous haematological, biochemical and biophysical markers have been used to screen the antenatal population topredict pregnancy induced hypertension over the past 60 years but none has been universally accepted due to low predictive values. Early trimester colour Doppler ultrasonography has an excellent role to play as a predictor of pregnancy induced hypertensionbut its accessibility in day to day practice is limited ${ }^{11}$. Our study was conducted to determine the possibility of using beta HCG which is readily available to predict pregnancy induced hypertension.

In our study the mean age of patients was $27.3 \pm 4.3$ which was similar to a study conducted by Kabukcu et al12, suggesting PIH to be common in women in their twenties. In the mid 1900 it was reported that HCG levels were elevated in toxemia of pregnancy. Patients in this study who had higher levels of serum beta HCG (>2MoM) during their second trimester were more likely to encounter PIH further down the line in their own pregnancy, ( $p$-value $<0.001)$. Of $83.3 \%$ of patients with elevated serum levels of beta HCG went on the develop PIH (sensitivity $96.1 \%$, specificity

Table-II: Stratification for gestational hypertention and beta HCG value.

\begin{tabular}{|c|c|c|c|c|c|c|c|c|c|c|c|c|c|}
\hline \multicolumn{2}{|c|}{$\begin{array}{l}\text { Gestational } \\
\text { hypertension }\end{array}$} & $\begin{array}{c}\text { HCG }>2 \\
\text { MOM }\end{array}$ & \multicolumn{2}{|c|}{$\begin{array}{c}\text { HCG } \\
<2 \mathrm{MOM}\end{array}$} & \multicolumn{2}{|c|}{$\begin{array}{l}\text { Sensitivity } \\
(95 \% \mathrm{CI})\end{array}$} & \multicolumn{2}{|c|}{$\begin{array}{c}\text { Specificity } \\
(95 \% \mathrm{CI})\end{array}$} & \multicolumn{2}{|c|}{$\begin{array}{c}\text { PPV } \\
(95 \% \mathrm{CI})\end{array}$} & $\begin{array}{c}\text { NPV } \\
(95 \% \text { CI }) \\
\end{array}$ & $\begin{array}{c}p- \\
\text { value }\end{array}$ & $\begin{array}{c}\text { Chi } \\
\text { Square }\end{array}$ \\
\hline \multicolumn{2}{|c|}{ Yes } & $\mathrm{TP}=25$ & \multicolumn{2}{|c|}{$\mathrm{FP}=5$} & \multirow{2}{*}{\multicolumn{2}{|c|}{$96.1 \%$}} & \multirow{2}{*}{\multicolumn{2}{|c|}{$97.3 \%$}} & \multirow{2}{*}{\multicolumn{2}{|c|}{$83.3 \%$}} & \multirow{2}{*}{$99.4 \%$} & \multirow{2}{*}{$<0.001$} & \multirow{2}{*}{165.64} \\
\hline No & & $\mathrm{FN}=1$ & $\mathrm{TN}=1$ & & & & & & & & & & \\
\hline \multicolumn{14}{|l|}{$T P=T$} \\
\hline & \multicolumn{2}{|c|}{$\begin{array}{c}\text { Gestational } \\
\text { Hyper- } \\
\text { tension }\end{array}$} & $\begin{array}{c}\text { HCG>2 } \\
\text { MOM }\end{array}$ & \multicolumn{2}{|c|}{$\begin{array}{c}\text { HCG<2 } \\
\text { MOM }\end{array}$} & \multicolumn{2}{|c|}{$\begin{array}{l}\text { Sensitivity } \\
\text { (95\% CI) }\end{array}$} & \multicolumn{2}{|c|}{$\begin{array}{l}\text { Specificity } \\
\text { (95\% CI) }\end{array}$} & $\begin{array}{c}\text { PPV } \\
(95 \% \\
\text { CI) }\end{array}$ & $\begin{array}{c}\text { NPV } \\
(95 \% \\
\text { CI })\end{array}$ & $\begin{array}{c}p \text { - } \\
\text { value }\end{array}$ & $\begin{array}{c}\text { Chi } \\
\text { square }\end{array}$ \\
\hline \multirow{2}{*}{$\begin{array}{l}\text { GA 13-14 } \\
\text { Weeks } \\
n=74\end{array}$} & & Yes & $\mathrm{TP}=10$ & \multicolumn{2}{|c|}{$\mathrm{FP}=0$} & \multirow{2}{*}{\multicolumn{2}{|c|}{$90.1 \%$}} & \multirow{2}{*}{\multicolumn{2}{|c|}{$100 \%$}} & \multirow[b]{2}{*}{$100 \%$} & \multirow[b]{2}{*}{$98.4 \%$} & \multirow[b]{2}{*}{$<0.001$} & \multirow[b]{2}{*}{66.222} \\
\hline & & No & $\mathrm{FN}=1$ & & $=63$ & & & & & & & & \\
\hline \multirow{2}{*}{$\begin{array}{l}\text { GA 15-16 } \\
\text { Weeks } \\
n=53\end{array}$} & \multicolumn{2}{|r|}{ Yes } & $\mathrm{TP}=4$ & \multicolumn{2}{|c|}{$\mathrm{FP}=1$} & \multirow{2}{*}{\multicolumn{2}{|c|}{$100 \%$}} & 97. & & $80 \%$ & $100 \%$ & $<0.001$ & 41.535 \\
\hline & & No & $\mathrm{FN}=0$ & & $=48$ & & & & & & & & \\
\hline $\begin{array}{l}\text { GA } 17-18 \\
\text { Weeks }\end{array}$ & & Yes & $\mathrm{TP}=11$ & & $=4$ & 100 & & 94.' & & $73.3 \%$ & $100 \%$ & $<0.001$ & 60.442 \\
\hline $\mathrm{n}=87$ & & no & $\mathrm{FN}=0$ & & $=72$ & & & & & & & & \\
\hline
\end{tabular}


97.3\%, PPV 83.3\%, NPV 99.4\% and diagnostic accuracy $97.2 \%$ ). Our results are comparable with the study of Kaur et al11, with $p$-value of $<0.01$ and positive predictive value of $83.3 \%$ which is the same as our study.

As pointed out by Rajesh et al13, prevention of PIH will follow if early prediction is possible. In that study serum beta HCG was estimated between 14-20 weeks of gestation in 90 women with singleton pregnancy. A total of (14.8\%) cases developed gestational hypertension. Levels of serum $\beta$-HCG were higher in subjects that developed gestational hypertension. Serum beta HCG (median $>32726 \mathrm{mIU} / \mathrm{ml}$ ) had a sensitivity of $75 \%$, specificity of $72.5 \%$, a PPV of $32.1 \%$ and an accuracy of $72.8 \%$.

Jindal also found a correlation between elevated serum beta HCG levels and PIH ${ }^{14}$. Kaur et al ${ }^{15}$ and colleagues observed that higher levels of beta HCG are associated with increased severity of PIH ( $p$-value $<0.01$ ). The sensitivity was $90.91 \%$, specificity was $97.44 \%$ and positive predictive value was $83.33 \%$. Thisfurther supports our finding that beta HCG has a valuable role in predicting $\mathrm{PIH}$.

$\mathrm{PIH}$ seldom develops after the second trimester, and the pathogenesis starts early in pregnancy ${ }^{16}$, as shown by stratification of gestational age and beta HCG levels in pregnant patients between 13-18 weeks of gestation ( $p$-value $<0.001$; significant). Similar results have been shown by Feng et al, who displayed the positive correlation between absolute levels of serum beta-HCG and the severity of pregnancy induced hypertension $(p \text {-value } \leq 0.05)^{17}$. To focus on high risk women and to identify them in time, screening has a pivotal role18.

\section{CONCLUSION}

An increased risk of gestational hypertension in gravid patients with high levels of beta HCG levels >2MoM at 13-18 weeks gestation was found. Beta HCG has shown to be a practical, reliable and readily available test for the prediction of PIH and should be used as a screening tool in pregnant women.

\section{CONFLICT OF INTEREST}

This study has no conflict of interest to be declared by any author.

\section{REFERENCES}

1. Sharma V, Sharma P, Firdous N. Beta HCG in mid trimester as a predictor of pregnancy induced hypertension. Int J Sci Res 2016; 5(9): 303-05.

2. Singh J, Singh S, Srivastava K, Chandra A, Kunwar S. $\beta$ HCG for screening of gestational hypertension: a prospective observational study in north Indian population. Era's J Med Res 2017; 4(1): 9-13.

3. Mehta B, Kumar V, Chawla S, Sachdeva S, Mahopatra D. Hypertension in pregnancy: a community-based study. Ind J Community Med 2015; 40(4): 273-78.

4. Gudeta TA, Regassa TM. Pregnancy induced hypertension and its associated factors among women attending delivery service at Mizan-Tepi university teaching hospital, Tepi and Gebretsadikshawo Hospitals, Southwest, Ethiopia. Ethiop J Health Sci 2018; 29(1): 831-40.

5. Chowdhary H, Khurshid R, Parveen S, Yousaf S, Tali SH, Shah ZA. Utility of second trimester beta HCG levels in prediction of gestational hypertension: a prospective cohort study. Int $\mathrm{J}$ Reprod Contracept Obstet Gynecol 2017; 6(3): 1040-44.

6. Anthony J, Damasceno A, Ojjii D. Hypertensive disorders of pregnancy: what the physician needs to know. Cardiovasc J Africa 2016; 27(2): 104-10.

7. Asiltas B, Surmen-Gur E, Uncu G. Prediction of first-trimester preeclampsia: Relevance of the oxidative stress marker MDA in a combination model with PP-13, PAPP-A and beta-HCG. Pathophysiol 2018; 25(2): 131-35.

8. Stampalija T, Quadrifoglio M, Casati D, Zullino S, Maggi V, Di Martino D, et al. First trimester placental volume is reduced in hypertensive disorders of pregnancy associated with small for gestational age fetus. J Maternal-Fetal Neonatal Med 2019; 1(1): $1-8$.

9. Panwar M, Kumari A, HP A, Arora R, Singh V, Bansiwal R. Raised neutrophil lymphocyte ratio and serum beta hCG level in early second trimester of pregnancy as predictors for development and severity of preeclampsia. Drug Discov Ther 2019; 13(1): 34-37.

10. Korevaar TI, Steegers EA, de Rijke YB, Schalekamp-Timmermans S, Visser WE, Hofman A, et al. Reference ranges and determinants of total hCG levels during pregnancy: the Generation R Study. Eur J Epidemiol 2015; 30(9): 1057-66.

11. Singh P, Sharma B, Singh N. Early prediction of pregnancy induced hypertension by colour Doppler and role of antioxidantsInt J Reprod Contracept Obstet Gynecol 2016; 5(8): 2677-79.

12. Kabukçu A, Önderoglu L, Laleli Y, Durukan T. Women with elevated second trimester human chorionic gonadotropin level are at increased risk for preeclampsia. Turk J Med Sci 1998; 28(3): 273-76.

13. Rajesh A, Muralidharan V. Serum beta hCG in early second trimester as a predictor of gestational hypertension. Int J Reprod Contracept Obstet Gynecol 2018; 7(6): 2355-59.

14. Jindal N. Prediction of maternal serum beta HCG levels in preeclamptic and normotensive pregnant women. Int J Clinical Obstet Gynaecol 2017; 1(2): 34-36.

15. Kaur G, Jain V, Mehta S, Himani S. Prediction of PIH by maternal serum beta HCG levels in the second trimester (13-20 weeks) of pregnancy. J Obstet Gynaecol Ind 2012; 62(1): 32-34. 
16. Gautam SS, Kaur M, Chaudhary NK, Sharma A. Evaluation of the variations and potential clinical use of second trimester serum markers for the detection of pre-eclampsia. Int J Reprod Contracept Obstet Gynecol 2018; 7(7): 2904-08.

17. Feng $Q$, Cui S, Yang W. Clinical significance of beta-hCG and human placental lactogen in serum of normal pregnancies and patients with pregnancy induced hypertension. Zhonghua $\mathrm{Fu}$ Chan Ke Za Zhi 2000; 35(11): 648-50.

18. Taher SI, Alalaf SK. Association between serum beta-human chorionic gonadotropin and preeclampsia and its effects on perinatal and maternal outcomes: a case control study. Archives Gynecol Obstetr 2019; 299(3): 713-8. 